\title{
Social and structural factors associated with depression and suicidality among men who have sex with men and transgender women in Nepal
}

Sanna Storm ${ }^{1}$, Keshab Deuba ${ }^{2^{*}}$, Rachana Shrestha ${ }^{3}$, Lok Raj Pandey ${ }^{4}$, Deepak Dahal ${ }^{4}$, Madan Kumar Shrestha ${ }^{4}$, Tara Nath Pokhrel ${ }^{5}$ and Gaetano Marrone ${ }^{1}$

\begin{abstract}
Introduction: The prevalence of depression and suicidality is high among men who have sex with men (MSM) and transgender women (TGW) worldwide. Stigma and discrimination are likely contributing factors. More research is needed in low-income, non-English speaking countries to assess the effects of social and structural factors on depression and suicidality among MSM and TGW.

Methods: Nepalese MSM and TGW ( $n=340$ ) were recruited using a respondent-driven sampling design and filled out a survey questionnaire. The outcomes were depression and suicidality. Data was analyzed using bivariate and multivariable logistic regression.

Results: More than half of the participants (59\%) suffered from depression. Severe depression was more common among TGW compared to MSM (41 and 20\%, respectively). When it comes to suicidality, TGW had higher lifetime prevalence of suicidal thoughts compared to MSM (32 and 5\%, respectively). Depression was positively associated with sex work both for MSM (AOR: 7.9; 95\% Cl 3.4-18.2) and TGW (AOR: 6.5; 95\% Cl: 2.3-18.2). MSM who were evicted by family had high odds of suicidal thoughts (AOR: 6.2; 95\% Cl: 1.3-28.8). For TGW, suicidality was associated with being cheated and threatened (AOR: 3.9; $95 \%$ Cl: 1.2-12.5) and having forced to marry a female (AOR: 2.2; 95\% Cl 1.1-5.1).

Conclusions: Nepalese MSM and TGW suffer from a high degree of mental and psychosocial health issues. Future studies should focus on intervention research and on collecting data from a larger variety of gender and sexual minorities.
\end{abstract}

Keywords: Sexual and gender minorities, MSM, TG, Discrimination, Depression, Suicidality, Low-income country

\footnotetext{
*Correspondence: deuba4k@gmail.com

${ }^{2}$ National Centre for AIDS and STD Control/Global Fund Programs, Kathmandu, Nepal

Full list of author information is available at the end of the article
}

(C) The Author(s). 2021 Open Access This article is licensed under a Creative Commons Attribution 4.0 International License, which permits use, sharing, adaptation, distribution and reproduction in any medium or format, as long as you give appropriate credit to the original author(s) and the source, provide a link to the Creative Commons licence, and indicate if changes were made. The images or other third party material in this article are included in the article's Creative Commons licence, unless indicated otherwise in a credit line to the material. If material is not included in the article's Creative Commons licence and your intended use is not permitted by statutory regulation or exceeds the permitted use, you will need to obtain permission directly from the copyright holder. To view a copy of this licence, visit http://creativecommons.org/licenses/by/4.0/. The Creative Commons Public Domain Dedication waiver (http://creativecommons.org/publicdomain/zero/1.0/) applies to the data made available in this article, unless otherwise stated in a credit line to the data. 


\section{Introduction}

Gender and sexual minorities are a group of individuals "whose sexual orientation or gender identity and reproductive development is considered outside cultural, societal, or physiological norms" [1]. Two groups that represent gender and sexual minorities are men who have sex with men (MSM) and transgender (TG) individuals. TG describes individuals who were assigned female or male sex at birth but whose gender identity does not match the assigned gender [2]. Stigma towards these groups common and a major cause of negative health outcomes $[3,4]$. Much of the research on gender and sexual minorities to this day has been conducted in high-income, English speaking countries and focused on physical health [5]. In recent years, growing evidence suggests similar results in studies conducted in low- and middle income countries in Asia [6-9]. In this study, we have focused on mental health aspects among MSM and TG women (TGW) in Nepal.

Compared to heterosexual individuals, sexual minorities are at a greater risk of suffering from psychosocial health problems including depression, suicidality, anxiety and substance abuse [10-12]. In Europe and North America, researchers have shown an association between non-heterosexual identity and mental health issues regardless of age, geographical location and which nonheterosexual orientation a person identifies with $[10,11$, 13-16]. When it comes to underlying reasons, a review article from 2018 comprising 35 American studies on depression among sexual minority youth identified several risk factors for depression, such as family rejection, experiences of negative social interactions and abuse, but also protective factors, such as self-esteem [13]. A review of 26 studies revealed that TG identity, as compared to a cis-gender (non-TG) identity, is also associated with a higher prevalence and rates of suicide [15]. The rate of suicidal thoughts amongst TG varied from 10 to $81 \%$ in these studies, and attempted suicide rates varied from 10 to $52 \%$.

The findings from Europe and North America on negative mental health aspects among gender and sexual minorities also appear in Southeast Asia [17-20]. According to United Nations Development Programme (UNDP) and Asia Pacific Transgender Network (APTN), discrimination is common in the fields of education, employment and health services as is physical, sexual and psychological abuse of the gender and sexual minorities $[2,21]$. In addition, the limited legal rights of these minorities might worsen their mental health [22]. In fact, in half of the Asian countries homosexuality is still illegal [2, 22]. Laws such as public nuisance, criminalization of sex work and prohibition of crossdressing are frequently used to target transgender individuals as reported by UNDP and APTN [2].
As a consequence of discrimination and lack of legal assistance, many minorities hide their sexual identity $[19,20]$. Appearing different than society's norm is a source of stigma, leading many TGW to choose in gender conforming clothing [20]. As reported by APTN and UNDP, discrimination and stigma are common on the job market, which can lead to unemployment [23]. This, in turn, sometimes leaves sex work as the only source of income, further increasing the stigma [19]. According to a Vietnamese study on $451 \mathrm{MSM}$, these stigmas might explain why they tend to suffer from increased rates of depression [18]. In the study, as many as $68 \%$ of the participants had clinically significant depression.

Although discrimination against minorities is common in Southeast Asia, Nepal can be considered an outlier because Nepal legally recognizes the third gender and the constitution encourages equal rights [21, 24]. In spite of this, gender and sexual minorities still face challenges in their day-to-day life $[25,26]$. The problem in Nepal seems be centered on social stigma. Family members, neighbors and other community members try to influence life choices of gender and sexual minorities towards a heteronormative way of living [25]. This discourages them from openly showing their sexual orientation or gender identity [25]. Consequently, homosexual men often marry females [2, 27, 28]. Furthermore, social stigma is also a source of negative feelings, having to be untruthful to family and friends when hiding one's true sexual identity [27]. Another consequence of the social stigma is a negative self-image, for example, due to verbal abuse in public areas. Other negative consequences include coerced sex, and being subjected to threats and violence.

Transgender communities in Nepal seem to be particularly vulnerable to social stigma and its consequences. Besides the above mentioned, they suffer from challenges such as discrimination, unemployment, violence and limited awareness and knowledge about sexual and gender minorities [29]. Furthermore, although it is legal in Nepal to have a gender and sexual minority identity, the public nuisance laws under the Public Offence Act [24] have been used to arrest members of gender and sexual minorities community $[2,30]$.

Although the difficulties faced by gender and sexual minorities are unlikely to leave this group of individuals unaffected, there is a great lack of research specifically focusing on mental health effects of such difficulties on these Nepalese minority groups [5]. Importantly, while recent reviews on this subject have been conducted in the USA or other English speaking and high-income countries [31], the question of negative health outcomes among gender and sexual minorities in low-income countries has only recently been raised on a sociological and psychosocial scientific level $[3,26]$. The negative 
health outcomes vary from physical and mental health, to work and family-related social relations [25, 32-34]. A deeper knowledge and more comprehensive understanding of the negative mental health outcomes among sexual and gender minorities might help to identify possible interventions that may lead to a positive change in attitudes and, most importantly, to a better mental and physical health [3, 34-36].

The aim of this study was to analyze the impact of social and structural factors on depression and suicidality among MSM and TGW in Nepal.

\section{Methods}

\section{Participants}

Secondary cross-sectional data [37] were used in this study. Gender and sexual minorities are a large and diverse group of individuals. Therefore, we limited the study population in this study to MSM and TGW. Both MSM and TGW refer to several self-identified gender identities and sexual orientations. A list and definitions of these is available in Table 1.

\section{Inclusion and exclusion criteria}

For inclusion in the study the participants must have been assigned male at birth, aged 16 years or above and engaged in sexual relationship (oral and/or anal sex) with another biological male at least once within the past 12 months prior to the date of study. There were no exclusion criteria other than previous participation in the study.

Table 1 Definition of gender identities and sexual orientations of the study participants

\begin{tabular}{|c|c|}
\hline Identity & Definition \\
\hline \multicolumn{2}{|l|}{$\overline{M S M}$} \\
\hline $\begin{array}{l}\text { Ta, panthi, } \\
\text { gay, male }\end{array}$ & $\begin{array}{l}\text { Men assigned male at birth who are perceived as } \\
\text { masculine, or "manly", and who have a penetrative } \\
\text { role when having sex with another man. }\end{array}$ \\
\hline Dohori & $\begin{array}{l}\text { "Both ways". Men assigned male at birth who have } \\
\text { no preferred role during sexual activity with another } \\
\text { man. }\end{array}$ \\
\hline \multicolumn{2}{|l|}{ TGW } \\
\hline Meti & $\begin{array}{l}\text { "A person who quenches a thirst", i.e., has a receiving } \\
\text { role in sexual activity. Transgender, feminine } \\
\text { appearing and often cross-dressing person that was } \\
\text { assigned male sex at birth. }\end{array}$ \\
\hline Meta & "A man who quenches a thirst". \\
\hline Kothi & Southeast Asian counterpart for meti. \\
\hline $\begin{array}{l}\text { Mougiya, } \\
\text { mouga }\end{array}$ & Local counterpart for meti in the Terai- region. \\
\hline Nachaniya & Feminine appearing biological male who is a dancer. \\
\hline
\end{tabular}

\section{Study area and data collection}

The data was collected in April 2018 from 340 Nepalese MSM and TGW in eight small cities in the Terai Highway districts in Southern Nepal [37]. The eight districts where the study was carried out were: Jhapa, Morang, Sunsari, Nawalparasi, Rupandehi, Kapilbastu, Kailali and Kanchanpur. These districts share an open border with India. Besides the Terai region, similar data has previously been collected in Nepal's two largest cities, Kathmandu (capital city) and Pokhara. Collecting data from the current districts provides a sample from smaller cities that all share an open border to India. This could potentially provide variations to the results compared with large city MSM- and TGW- population. The sample size was sufficient to detect a $15-\%$ point difference according to a power analysis [37].

\section{Instruments and measures \\ Respondent-driven sampling}

The participants were recruited by respondent-driven sampling (RDS). Generally, when using RDS, initial participants called "seeds" are identified [38]. In the current study there were eight seeds from various groups (regarding for example age, gender identity or sexual orientation) from each study district [37]. After participation in the study, each seed received three recruitment coupons that they gave to MSM and TGW within their social network. These participants, in turn, received recruitment coupons after completed participation. Participants reported their network size which was used to calculate RDS-weighted values.

The data was collected by face-to-face interviews using a semi-structured Integrated Biological and Behavioral Surveillance (IBBS) survey [37]. IBBS has been used in Nepal for HIV surveillance purposes for several years. The IBBS included questions about socio-demographic, structural, social and psychosocial factors. A list of the included factors is provided in Table 2. Information about sexual behavior and sexually transmitted diseases was also collected, but not used in this study. This was also the first time the IBBS data from Terai was used to assess psychosocial health problems among MSM and TGW.

The participants were first briefly screened to ensure that they met the inclusion criteria. After giving informed consent, participants were first interviewed to collect the behavioral data and then received pre-test counseling, before collection of biological specimen and health and STI checkup. Before finishing the survey process, they received test results as well as post-test counseling and referral for available services as per need [37].

\section{Socio-demographic factors}

Age was dichotomized to $\leq 30$ (17-30 years old) and > 30 (31-62 years old). Literate participants, with or 
Table 2 Descriptive statistics among 340 MSM and TGW in Nepal (RDS-weighted values)

\begin{tabular}{|c|c|c|c|}
\hline Characteristics & MSM $(n=201,77 \%) n(\%)$ & TGW $(n=139,23 \%) n(\%)$ & $\begin{array}{l}\text { Total } \\
n(\%)\end{array}$ \\
\hline \multicolumn{4}{|l|}{ Socio-demographic factors } \\
\hline \multicolumn{4}{|l|}{ Age } \\
\hline$\leq 30$ & $133(66)$ & $67(48)$ & $200(59)$ \\
\hline$>30$ & $68(34)$ & $72(52)$ & $140(41)$ \\
\hline \multicolumn{4}{|l|}{ Education } \\
\hline Illiterate & $16(6)$ & $19(11)$ & $35(7)$ \\
\hline Literate & $168(86)$ & $104(76)$ & $272(84)$ \\
\hline Literate without formal education & $17(8)$ & $16(13)$ & $33(9)$ \\
\hline \multicolumn{4}{|l|}{ Gender identity } \\
\hline Third gender & $38(13)$ & $99(63)$ & $137(24)$ \\
\hline Female & $0(0)$ & $28(20)$ & $28(4)$ \\
\hline Male & $163(87)$ & $12(17)$ & $175(72)$ \\
\hline \multicolumn{4}{|l|}{ Marital status } \\
\hline Married & $75(28)$ & $52(34)$ & $127(29)$ \\
\hline Not married & $126(72)$ & $87(66)$ & $213(71)$ \\
\hline \multicolumn{4}{|l|}{ Main profession } \\
\hline Student & $60(40)$ & $3(6)$ & $63(33)$ \\
\hline Driver & $9(4)$ & $0(0)$ & $9(3)$ \\
\hline Civil servant & $6(3)$ & $0(0)$ & $6(2)$ \\
\hline Businessman & $17(6)$ & $19(11)$ & $36(7)$ \\
\hline Private company staff & $23(8)$ & $16(12)$ & $39(11)$ \\
\hline Laborer/wage labor & $54(28)$ & $22(21)$ & $76(24)$ \\
\hline Artist & $5(2)$ & $23(11)$ & $28(5)$ \\
\hline Farmer & $11(4)$ & $11(14)$ & $22(6)$ \\
\hline Sex worker & $8(2)$ & $34(15)$ & $42(4)$ \\
\hline Unemployed & $8(3)$ & $11(10)$ & $19(5)$ \\
\hline \multicolumn{4}{|l|}{ Sex work past 12 months } \\
\hline Yes & $25(6)$ & $87(51)$ & $112(16)$ \\
\hline No & $176(94)$ & $52(49)$ & $228(84)$ \\
\hline \multicolumn{4}{|l|}{ Income in NPR } \\
\hline No income & $29(19)$ & $6(8)$ & $35(17)$ \\
\hline$<10,000$ & $31(13)$ & $28(28)$ & $59(17)$ \\
\hline $10,000-19,999$ & $64(27)$ & $53(33)$ & $117(28)$ \\
\hline $20,000-29,999$ & $18(9)$ & $22(15)$ & $40(10)$ \\
\hline$\geq 30,000$ & $24(9)$ & $23(8)$ & $47(9)$ \\
\hline \multicolumn{4}{|l|}{ Structural factors } \\
\hline \multicolumn{4}{|c|}{ Cross-border movement for sexual activity } \\
\hline Yes & $45(13)$ & $42(20)$ & $87(15)$ \\
\hline No & $156(87)$ & $97(80)$ & $253(85)$ \\
\hline \multicolumn{4}{|c|}{ Experience of violence based on sexual orientation } \\
\hline \multicolumn{4}{|l|}{ Physical abuse } \\
\hline Yes & $6(1)$ & $19(8)$ & $25(3)$ \\
\hline No & $195(99)$ & $120(92)$ & $315(97)$ \\
\hline
\end{tabular}


Table 2 Descriptive statistics among 340 MSM and TGW in Nepal (RDS-weighted values) (Continued)

\begin{tabular}{|c|c|c|c|}
\hline Characteristics & MSM $(n=201,77 \%) n(\%)$ & TGW $(n=139,23 \%) n(\%)$ & $\begin{array}{l}\text { Total } \\
n(\%)\end{array}$ \\
\hline \multicolumn{4}{|l|}{ Forced sex } \\
\hline Yes & $8(1)$ & $31(1)$ & $39(4)$ \\
\hline No & $193(99)$ & $108(99)$ & $301(96)$ \\
\hline \multicolumn{4}{|l|}{ Cheated or threatened } \\
\hline Yes & $22(7)$ & $40(7)$ & $62(9)$ \\
\hline No & $179(93)$ & $99(93)$ & $278(91)$ \\
\hline \multicolumn{4}{|c|}{ Discrimination based on sexual orientation in different settings } \\
\hline \multicolumn{4}{|l|}{ At school } \\
\hline Yes & $32(11)$ & $52(27)$ & $84(15)$ \\
\hline No & $169(89)$ & $87(73)$ & $256(85)$ \\
\hline \multicolumn{4}{|l|}{ Job hunting } \\
\hline Yes & $12(2)$ & $25(12)$ & $37(4)$ \\
\hline No & $189(98)$ & $114(88)$ & $303(96)$ \\
\hline \multicolumn{4}{|l|}{ At work } \\
\hline Yes & $23(6)$ & $57(29)$ & $80(11)$ \\
\hline No & $178(94)$ & $82(71)$ & $260(89)$ \\
\hline \multicolumn{4}{|l|}{ Getting housing } \\
\hline Yes & $5(1)$ & $27(12)$ & $32(3)$ \\
\hline No & $196(99)$ & $112(88)$ & $308(97)$ \\
\hline \multicolumn{4}{|l|}{ Medical care } \\
\hline Yes & $7(1)$ & $97(22)$ & $49(6)$ \\
\hline No & $194(99)$ & $42(78)$ & $291(94)$ \\
\hline \multicolumn{4}{|c|}{ Service in store or restaurant } \\
\hline Yes & $22(6)$ & $62(33)$ & $84(12)$ \\
\hline No & $179(94)$ & $77(67)$ & $256(88)$ \\
\hline \multicolumn{4}{|c|}{ On the street or in a public setting } \\
\hline Yes & $28(7)$ & $87(54)$ & $115(16)$ \\
\hline No & $173(93)$ & $52(46)$ & $225(84)$ \\
\hline \multicolumn{4}{|c|}{ From police or other security personnel } \\
\hline Yes & $24(7)$ & $58(26)$ & $82(11)$ \\
\hline No & $177(93)$ & $81(74)$ & $258(89)$ \\
\hline \multicolumn{4}{|c|}{ Number of settings in past 12 months } \\
\hline None & $139(81)$ & $31(38)$ & $170(71)$ \\
\hline 1 setting or more & $62(19)$ & $108(62)$ & $170(29)$ \\
\hline \multicolumn{4}{|l|}{ Social factors } \\
\hline \multicolumn{4}{|c|}{ Forced marriage with a female } \\
\hline Yes & $69(26)$ & $81(53)$ & $150(32)$ \\
\hline No & $132(74)$ & $58(47)$ & $190(68)$ \\
\hline \multicolumn{4}{|c|}{ Evicted by family based on sexual orientation } \\
\hline Yes & $14(2)$ & $46(22)$ & $60(7)$ \\
\hline No & $187(98)$ & $93(78)$ & $280(93)$ \\
\hline \multicolumn{4}{|c|}{ Family acceptance of sexual orientation } \\
\hline Yes & $37(13)$ & $55(26)$ & $92(16)$ \\
\hline
\end{tabular}


Table 2 Descriptive statistics among 340 MSM and TGW in Nepal (RDS-weighted values) (Continued)

\begin{tabular}{|c|c|c|c|}
\hline Characteristics & MSM $(n=201,77 \%) n(\%)$ & TGW $(n=139,23 \%) n(\%)$ & $\begin{array}{l}\text { Total } \\
n(\%)\end{array}$ \\
\hline No & $164(87)$ & $84(74)$ & $248(84)$ \\
\hline \multicolumn{4}{|l|}{ Psychosocial factors } \\
\hline \multicolumn{4}{|l|}{ Depression (CESD-R) } \\
\hline Euthymic & $81(46)$ & $31(27)$ & $112(41)$ \\
\hline Distress & $63(34)$ & $45(34)$ & $108(34)$ \\
\hline Severe depression & $57(20)$ & $63(41)$ & $120(25)$ \\
\hline \multicolumn{4}{|c|}{ Lifetime prevalence of suicidal thoughts } \\
\hline Yes & $20(5)$ & $58(32)$ & $78(11)$ \\
\hline No & $181(95)$ & $81(68)$ & $262(89)$ \\
\hline \multicolumn{4}{|c|}{ Suicidal thoughts past 12 months } \\
\hline Once or twice & $12(79)$ & $14(14)$ & $26(36)$ \\
\hline A few times & $4(8)$ & $23(53)$ & $27(38)$ \\
\hline Many times & $3(8)$ & $21(33)$ & $24(36)$ \\
\hline No response & $1(5)$ & $0(0)$ & $1(2)$ \\
\hline \multicolumn{4}{|c|}{ Lifetime prevalence of suicidal plans } \\
\hline Yes & $9(26)$ & $38(51)$ & $47(43)$ \\
\hline No & $11(74)$ & $20(49)$ & $31(57)$ \\
\hline \multicolumn{4}{|c|}{ Lifetime prevalence of attempted suicide } \\
\hline Yes & $6(15)$ & $26(28)$ & $32(23)$ \\
\hline No & $14(85)$ & $32(72)$ & $46(77)$ \\
\hline \multicolumn{4}{|c|}{ Alcohol consumption past 4 weeks } \\
\hline None & $86(41)$ & $73(61)$ & $159(46)$ \\
\hline At least once a week & $109(56)$ & $54(34)$ & $163(51)$ \\
\hline Every day & $6(3)$ & $12(5)$ & $18(4)$ \\
\hline \multicolumn{4}{|c|}{ Drug abuse past 12 months } \\
\hline Yes & $25(8)$ & $7(1)$ & $32(7)$ \\
\hline No & $176(92)$ & $132(99)$ & $308(93)$ \\
\hline
\end{tabular}

MSM Men who have sex with men; TGW Transgender woman; RDS Respondent-driven sampling; $n$ : sub-sample size; NPR Nepalese Rupees; CESD-R Center for Epidemiologic Studies Scale Revised

without formal education were merged into one literate category, resulting in categories literate and illiterate. The sexual orientation/gender identity variable was merged into two categories with following division: ta, man/mard, gay, panthi to MSM and meti/meta, Kothi, woman, transgender to TGW. For more details regarding the terminology, see Table 1. Sex work was assessed by asking if a participant had had sex with a male or a meti for money in the past 12 months. Participants were also asked to report last month's income in Nepalese rupees (NPR) and this was reported with categories <10,000, 10,000-19,999, $20,000-29,999$ and $\geq 30,000$. Prior to logistic regression analysis the income was dichotomized using the mean income $(15,000 \mathrm{NPR})$ as a cut-off.

\section{Structural factors}

Information on cross-border movement for sexual activity was collected by asking the participants whether they had crossed the open border to India for anal or oral sex the past 12 months (yes/no). Experience of violence was measured by yes/no- questions about physical abuse, forced sex and cheated or threatened.

\section{Self-perceived discrimination}

Self-perceived discrimination was measured using the self-report instrument Experiences of Discrimination (EOD) [39]. Firstly, participants were asked to answer whether or not they had experienced discrimination in different settings. These settings in the current study were at school, getting hired or getting a job, at work, 
getting housing (renting or buying), getting medical care, getting service in a store or restaurant, on a street or in a public setting (park), from the police/other security personnel [40]. Secondly, a summary was made of the number of settings where a participant had experienced discrimination (none, 1 setting or more).

\section{Social factors}

The social factors included questions about the participant's family forcing them to marry a female (yes/no), family evicting the participant based on their sexual orientation (yes/no), and family acceptance of one's sexual orientation by having at least one person within the family who the participant can openly talk to when it comes to their sexual orientation (yes/no).

\section{Psychosocial factors}

Aside from depression and suicidality below, other psychosocial factors include Alcohol consumption in the past 4 weeks, measured by adding the participants that never had drunk alcohol into the "none"- category thus creating three categories: none, at least once a week and every day. The same was done for prevalence of drugs abuse in the past 12 months. Participants reporting use of any drug were categorized as yes and the ones who never had used drugs were added to the category of participants who did not report specific drugs used in the past 12 months.

\section{Depression}

The primary outcome of interest, depression, was measured by Center of Epidemiological Studies Depression Scale Revised (CESD-R). The CESD-R consists of 20 selfreported questions [41]. The questions in the revised scale cover depressive symptoms defined by the fifth edition of Diagnostic and Statistical Manual (DSM-5), including $d y s$ phoria, loss of interest, appetite, sleep, thinking/concentration, guilt, tiredness, agitation and suicidal ideation [42]. In this study, the cutoff of 16 points of 60 possible was considered to correspond to a clinically significant depressive disorder [41]. Score for severe depression was set to 22 points, as used in previous studies [36]. The instrument has relatively high reliability and validity for research purposes [41, 43] and for depression assessment in both key and general population [44].

\section{Suicidality}

The secondary outcome of interest, suicidality, was measured by self-reported suicidal thoughts. All participants were asked whether they ever felt so low that they thought about committing suicide. For the ones that reported such thoughts, three additional questions were asked ("How often did you have any thought about ending your own life in last 12 months?", "Have you ever made a plan to commit suicide?" and "Did you ever attempt suicide?"). However, the three additional questions were not included as outcomes of interest in the final analysis due to small sample size. The questions were extracted from DSM-5.

\section{Statistical methods}

We used IBM SPSS Statistics 25 (SPSS Inc., Chicago, IL, USA) in data analysis, and STATA 15 (StataCorp, College Station, Texas, USA) for RDS-weighted analysis. We performed a descriptive statistics analysis of the different variables, using frequencies and percentages for categorical variables, and mean and standard deviation for continuous variables. Bivariate and multivariable logistic regression analyses were then conducted to estimate crude odds ratio (OR) and adjusted odds ratio (AOR), respectively, and their 95\% confidence intervals (CI). The dependent factors (outcomes of interest) in these analyses were depression and suicidality.

\section{Results}

Most of the 340 participants were MSM ( $n=201,77 \%)$, and rest were TGW $(n=139,23 \%)$. The mean age of the participants was 29 years (SD 10.12), ranging from 17 to 62 years. The majority of TGW identified as third gender (63\%) whereas most of the MSM reported a male identity $(87 \%)$. Most of the participants were literate (93\%), but more of the MSM had a formal education (86\%) than the TGW (76\%). The most common main profession among all participants was student (33\%), followed by wage labor $(24 \%)$. Four percent of all participants listed sex work as their main profession, but 16\% reported having earned money by selling sex during the past 12 months. The mean income per month was 15,000 NPR (SD 15900), which is equivalent to 134 U.S. dollars. For detailed descriptive statistics with RDSweighted values, see Table 2 .

Regarding the structural factors, 87 (15\%) participants reported having crossed the open border to India for the purpose of sexual activity in the past year. Physical abuse based on sexual orientation was more common among TGW $(n=19 ; 8 \%)$ compared to MSM $(n=6 ; 1 \%)$. Both MSM and TGW reported the same rates of forced sex or being cheated or threatened based on sexual orientation (1 and 7\%, respectively).

The mean number of settings where discrimination was experienced was 1.66 (SD 2.16). One-fifth of all MSM and three out of five TGW reported having suffered discrimination in more than one setting. TGW reported higher rates of discrimination compared to MSM in all eight settings. TGW experienced discrimination most commonly on streets or in public settings $(n=87$; $54 \%)$ whereas MSM experienced most discrimination in school $(n=32 ; 11)$. 
Regarding social factors, almost $1 / 3$ of the participants' families had forced, or attempted to force, them to marry a female. Specifically, over half of the TGW participants reported forced marriage compared to a quarter of MSM. Sixty participants (7\%) had been evicted by their families based on sexual orientation. This rate was much higher among TGW compared to MSM (22 and $2 \%$, respectively). Interestingly, family acceptance of sexual orientation was twice as common among TGW when compared to MSM (26\% compared to $13 \%$ ).

Generally, TGW reported more psychosocial health problems compared to MSM. Half of all participants drank alcohol at least once a week, but only $4 \%$ drank every day. Most of the participants who drank alcohol at least once a week were MSM (56\% compared to $34 \%$ of TGW) whereas TGW had a greater occurrence of drinking every day (5\% compared to $3 \%$ of MSM). Less than one in ten had used drugs during the past year, most of the drug users being MSM.

\section{Depression}

Of all participants, 59\% reached the cutoff score of 16 points on CESD-R. Equal rates of MSM and TGW, 34\%, had a depression score between 16 and 21. More than twice as many TGW had severe depression compared to MSM (see Fig. 1 for RDS-weighted rates of depression).

\section{Suicidality}

Almost one-third of TGW had ever had suicidal thoughts compared to 5\% among MSM. Of the participants reporting ever having had suicidal thoughts, over half of the TGW had made plans to commit suicide, and almost one third had attempted suicide. For comparison between MSM and TGW, see Fig. 2 for RDS-weighted rates of suicidal thoughts.

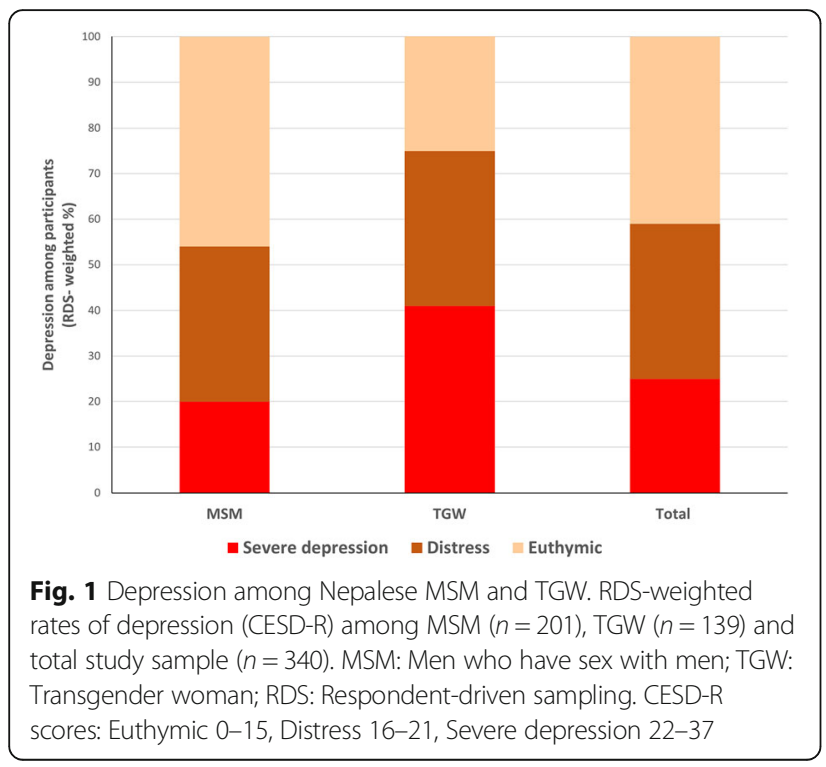

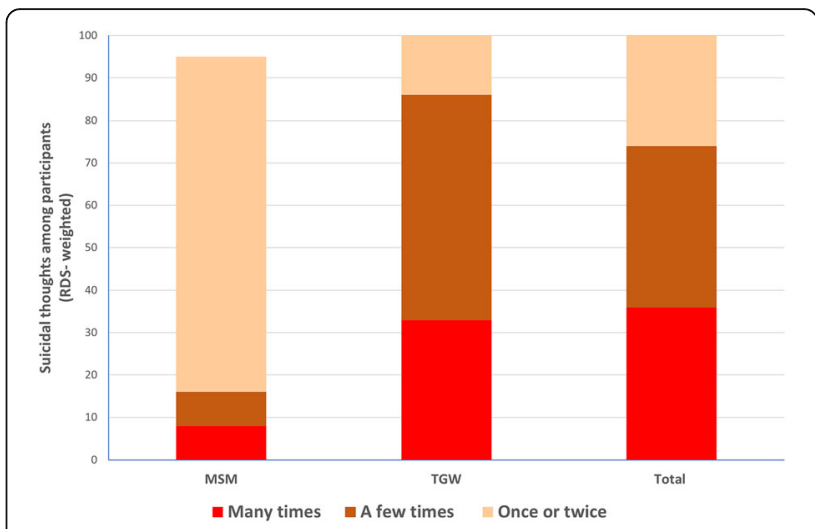

Fig. 2 Suicidal thoughts among Nepalese MSM and TGW. RDSweighted rates of suicidal thoughts in past 12 months among MSM $(n=19)$, TGW $(n=58)$ and total study sample $(n=77)$. MSM: Men who have sex with men; TGW: Transgender woman

\section{Risk factors among MSM}

As seen in Supplementary Table 1, eight different exposures were significant predictors of both depression and suicidality among Nepalese MSM. Two remained significant after including all exposures simultaneously in a multivariable logistic regression (see Table 3). Sex workers were more likely to report depression (AOR: 7.9; 95\% CI: 3.4-18.2). The MSM who were evicted by their family based on sexual orientation were more likely to have suicidal thoughts (AOR: 6.2; 95\% CI: 1.3-28.8).

\section{Risk factors among TGW}

Using bivariate logistic regression, we found several exposures that were significant predictors of depression and suicidality among Nepalese TGW (see Supplementary Table 2). As seen in Table 4, sex work (AOR: 6.5;

Table 3 Effect of socio-demographic, structural, social and psychosocial factors on depression (CESD-R) and suicidality among 201 MSM

\begin{tabular}{|c|c|c|c|}
\hline Variables & $\begin{array}{l}n \\
(\%)\end{array}$ & $\begin{array}{l}\text { Crude OR } \\
(95 \% \mathrm{Cl})\end{array}$ & $\begin{array}{l}\text { Adjusted OR } \\
\mathrm{b}_{(95 \% \mathrm{Cl})}\end{array}$ \\
\hline \multicolumn{4}{|l|}{ Depression } \\
\hline \multicolumn{4}{|c|}{ Socio-demographic factors } \\
\hline \multicolumn{4}{|c|}{ Sex worker } \\
\hline No & $43(36)$ & ref & ref \\
\hline Yes & $77(64)$ & $12.7(5.9-27.1)$ & $7.9(3.4-18.2)$ \\
\hline \multicolumn{4}{|l|}{ Suicidality } \\
\hline \multicolumn{4}{|c|}{ Social factors } \\
\hline \multicolumn{4}{|c|}{ Evicted by family based on sexual orientation } \\
\hline No & $12(60)$ & ref & ref \\
\hline Yes & $8(40)$ & $19.4(5.8-65.1)$ & $6.2(1.3-28.8)$ \\
\hline
\end{tabular}

CESD-R Center for Epidemiologic Studies Scale Revised; MSM Men who have sex with men; $O R$ Odds ratio; $n$ sub-sample size; $C l$ Confidence interval; ref reference category. See Supplementary Table 1 for all factors used in the bivariate and multivariable logistic regression 
Table 4 Effect of socio-demographic, structural, social and psychosocial factors on depression (CESD-R) and suicidality among 139 TGW

\begin{tabular}{|c|c|c|c|}
\hline Variables & $\begin{array}{l}n \\
(\%)\end{array}$ & $\begin{array}{l}\text { Crude OR } \\
(95 \% \mathrm{Cl})\end{array}$ & $\begin{array}{l}\text { Adjusted OR } \\
{ }^{\mathrm{b}}(95 \% \mathrm{Cl})\end{array}$ \\
\hline \multicolumn{4}{|l|}{ Depression } \\
\hline \multicolumn{4}{|c|}{ Socio-demographic factors } \\
\hline \multicolumn{4}{|c|}{ Sex worker } \\
\hline No & $12(11)$ & ref & ref \\
\hline Yes & $96(89)$ & $11.1(4.3-28.1)$ & $6.5(2.3-18.2)$ \\
\hline \multicolumn{4}{|l|}{ Suicidality } \\
\hline \multicolumn{4}{|c|}{ Structural factors } \\
\hline \multicolumn{4}{|c|}{ Cheated or threatened } \\
\hline No & $30(52)$ & ref & ref \\
\hline Yes & $28(48)$ & $5.3(2.4-11.9)$ & $3.9(1.2-12.5)$ \\
\hline \multicolumn{4}{|c|}{ Social factors } \\
\hline \multicolumn{4}{|c|}{ Forced marriage with a female } \\
\hline No & $17(29)$ & ref & ref \\
\hline Yes & $41(71)$ & $2.4(1.2-5.1)$ & $2.2(1.1-5.1)$ \\
\hline
\end{tabular}

CESD- $R$ Center for Epidemiologic Studies Scale Revised; TGW Transgender woman; $O R$ Odds ratio; $n$ : sub-sample size; $C l$ Confidence interval; ref reference category. See Supplementary Table 2 for all factors used in the bivariate and multivariable logistic regression

95\% CI: 2.3-18.2) remained significant for depression after multivariable logistic regression. Participants who had been cheated and threatened (AOR: 3.9; $95 \% \mathrm{CI}$ 1.2-12.5) and forced to marry a female (AOR: 2.2; 95\% CI: 1.1-5.1) had higher odds of suicidal thought.

\section{Discussion}

In this study, we aimed to analyze the impact of social and structural factors on depression and suicidality among MSM and TGW in Nepal. After multivariable analyses, several risk factors remained significant for depression and suicidality among MSM and TGW. We were also able to show that there are differences in several demographic factors between MSM and TGW in that TGW tended to suffer more discrimination.

\section{Strengths and limitations}

This quantitative study had several strengths, including that the data were collected from a wide age span [1762 ] and from municipalities that were both rural and included smaller cities (as opposed to large cities and metropolitan areas). In terms of methodology, the strength of this study is that recruiting participants was done with a validated sampling technique, RDS. The descriptive statistics are RDS- weighted thus providing more generalizable statistics. Besides RDS, even selfperceived discrimination, depression and suicidality were measured with standardized tools.
As for limitations in methodology, alcohol abuse was not measured with a standardized tool. Although RDS as a method has aimed to correct the flaws of its predecessor, that is, the snowball sampling method [38], it has yet to reach its full potential [45].

The cross-sectional nature of data collection for this study also leaves a question of how the psychosocial health issues developed over time in this sample [5]. Another limitation of the current study is that no comparison data from heterosexual cis-men or -women was collected. The findings of our study might be used to plan targeted interventions to improve mental health among gender and sexual minorities in Nepal. Although it is evident that the need for mental health services and prevention programs is great, there are no mental health services for gender and sexual minorities in the Terai region (Personal communication Ram Dev Tharu and Mamta Rai 1 Apr 2019). Furthermore, there is very limited mental health services available in the rest of the country (Personal communication Pinky Gurung 22 Mar 2019; Raju Thakali 25 Mar 2019). This leads to peer counseling often being the only option for help.

\section{Depression and suicidality}

As many as $75 \%$ of TGW and 54\% of MSM had clinically significant depression. Rates of depression are higher in our study compared to similar study in India where $42.7 \%$ of TGW and $35.3 \%$ of MSM had moderate to severe depression [46]. This study did however illustrate higher rates of depression among TGW compared to MSM. Another study on Indian MSM used CESD-R and found that $55 \%$ of participants met the cutoff criteria of 16 points, which is similar to our results [47]. Yet another study from India on psychiatric morbidities among TG showed that $31.2 \%$ suffered from current depression and $18.7 \%$ of dysthymia [48]. When it comes to suicidality, nearly $1 / 3$ of TGW and 5\% of MSM had ever had suicidal thoughts. Similar results in TGW, but higher rates among MSM have been reported by researchers in the U.S. $[49,50]$.

One significant factor contributing to suicidal ideation among TGW was forced marriage to a female. Not many published studies have found this association. Authors of a study of Kenyan MSM found lower depression scores among MSM who are married to a woman, and discuss the possibility that marriage to a woman could help MSM to conceal their sexual orientation [51]. They do not, however, mention whether or not the marriages are forced by family.

Nepal shares a long open border to India. Crossing this open border for sexual activities is a unique phenomenon that can hardly be expected to be found in many other regions. We found no articles where similar association was studied or found. To gain better 
understanding, we conducted interviews with individuals associated with gender and sexual minority rights movement in Nepal. In the Terai region, TGW sometimes sign contracts to provide sexual services to Nepali or Indian men, or to act as their partner for a certain period of time in exchange for money, accommodation or food (Personal communication Ram Dev Tharu and Mamta Rai 1 Apr 2019). Often these contracts are broken, possibly leaving TGW vulnerable with neither income nor accommodation. This could be one of the explanations to higher rates of depression and suicidality for individuals crossing the border (see Table 2), and even for sex workers and the ones reporting having been cheated or threatened. Threats and verbal abuse due to gender and sexual minority status, coming both from strangers and close ones, have been found to predict suicidality in other studies $[49,50]$.

Lack of social support was evident amongst many of the participants. Firstly, they could not openly talk about their own sexuality with their families, and secondly, many had been evicted by their family. Being evicted by family remained a significant risk factor for suicidality among MSM. Family rejection has in previous studies been associated with health problems such as suicide attempts, depression and use of drugs [52]. Evicted individuals in Nepal tended to move to larger cities and live under unstable housing conditions, for instance, with friends. Given that as many as half of the participants perceived discrimination in at least one setting, including the housing and working market, vulnerability for social problems among MSM and TGW is evident.

Unfortunately, this sometimes leaves sex work as the only solution for managing financially. Not only family problems [52] and lack of social support, but also being a sex worker increases the risk of having depression and displaying suicidal behavior. For both MSM and TGW, sex work remained as a significant factor for depression. Our findings support the analysis made in an Indian study, where sex work and depressive symptoms had positive correlation among MSM and TGW [53].

A larger proportion of the TGW experienced discrimination compared to MSM as seen in descriptive statistics (Table 2). A study from the U.S. found a high prevalence of attempted suicide among TG, with discrimination and depression among significant factors [54]. TGW tend to be more open about their sexuality compared to MSM who tend to be more afraid and attempt to hide their sexual identity [19], which could be one explanation to the higher rates of discrimination in our study.

In 2003, Meyer reviewed literature on how stress affects mental health among gender and sexual minorities [55]. Meyer summarized the findings of different (mostly American) studies and coined the minority stress theory.
The theory posits that stressors such as adverse family factors and discrimination lead to mental health problems in an additive fashion. Our findings describe some of the possible stressors for Nepalese MSM and TGW. It follows that Meyer's theory about higher prevalence of mental health problems among minorities, including gender and sexual minorities due to stress based on minority status, might be valid even in low-income, nonEnglish speaking countries.

\section{Conclusions}

Nepalese MSM and TGW suffer from a high degree of depression and suicidality. A factor increasing risk for depression among both MSM and TGW was sex work. Being evicted by family was associated with suicidality among MSM. For TGW, the associated factors for suicidality were being cheated or threatened and forced marriage to a female. Considering high burden of mental health issues among study population, it is vital to launch a mental health service program that reaches the gender and sexual minorities who already are suffering, as well as the minorities at risk to prevent and remedy mental health issues. However, mental and psychosocial health services and availability of mental health specialists are very limited in Nepal. It is also an utmost priority to generate evidence by implementing and evaluating effectiveness of peer-lead interventions to address high burden of mental health issues such as psychological distress among MSM and TG in Nepal.

\section{Supplementary Information}

The online version contains supplementary material available at https://doi. org/10.1186/s12888-021-03477-8.

Additional file 1. Sexual orientations and gender identities of study participants.

Additional file 2: Supplementary Table 1. Effect of socio-

demographic, structural, social and psychosocial factors on depression (CESD-R) and suicidality among 201 MSM. Supplementary Table 2. Effect of socio-demographic, structural, social and psychosocial factors on depression (CESD-R) and suicidality among 139 TGW.

\section{Acknowledgements}

We would like to thank Pinky Gurung, president of Blue Diamond Society, for sharing knowledge and for connecting us with other key stakeholders in Nepal to support the interpretation of quantitative findings. Some of the key stakeholders we would like to extend our gratitude to are Raju Thakali, Ram Dev Tharu and Mamta Rai, as well as the anonymous representatives of gender and sexual minorities that we had the true pleasure interviewing in order to better understand the local context to support the interpretation of quantitative findings. We would also like to thank Mika Johanson for writing assistance.

\section{Authors' contributions}

KD conceived and designed the study. Contributed to the primary data collection and data management for IBBS survey, contributed in statistical analyses, discussed the results, revised and commented on the article. SS analyzed and interpreted the unweighted participant data, whereas RS supported in weighted analysis. SS with contributions from all co-authors $(K D, R S, L R P, D D, M S, T N P, G M)$, drafted the manuscript. All co-authors 
discussed the results, revised and commented on the manuscript. The author(s) read and approved the final manuscript.

\section{Funding}

The study was funded by a national grant of The Global Fund to Fight AIDS, Tuberculosis and Malaria. The funder had no role in study design, data collection and analysis, decision to publish, or preparation of the manuscript.

\section{Availability of data and materials}

The datasets used and/or analyzed during the current study are available from the corresponding author on reasonable request.

\section{Declarations}

\section{Ethics approval and consent to participate}

Nepal Health Research Council approved the collection of the data for study (reg. no.: 90/2018). All methods were carried out in accordance with ethical and human rights standards. Field staff collected written informed consent from each participant prior to participation in study. The data were collected and managed anonymously, thus minimizing the risk of harm for the participants of the study. A counselor was present during the data collection and informed participants of available health care services, including mental health services for the suicidal participants.

\section{Consent for publication}

Not applicable.

\section{Competing interests}

The authors declare that they have no competing interests.

\section{Author details}

${ }^{1}$ Department of Global Public Health, Karolinska Institutet, Stockholm, Sweden. ${ }^{2}$ National Centre for AIDS and STD Control/Global Fund Programs, Kathmandu, Nepal. ${ }^{3}$ Public Health and Environment Research Centre, Lalitpur, Nepal. ${ }^{4}$ National Centre for AIDS and STD Control, Ministry of Health and Population, Kathmandu, Nepal. ${ }^{5}$ Family Welfare Division, Department of Health Services, Ministry of Health and Population, Kathmandu, Nepal.

\section{Received: 12 February 2021 Accepted: 13 September 2021}

\section{Published online: 29 September 2021}

\section{References}

1. Svensk MeSH [Internet]. Stockholm: Karolinska institutet. Universitetsbiblioteket; 1998 -. [cited 2019 May 09]. Available from: https:// mesh.kib.ki.se/term/D000072339/sexual-and-gender-minorities

2. Asia Pacific Forum of National Human Rights Institutions, United Nations Development Programme. Promoting and Protecting Human Rights in relation to Sexual Orientation, Gender Identity and Sex Characteristics: A Manual for National Human Rights Institutions [Internet]. Sydney: Asia Pacific Forum of National Human Rights Institutions; 2016. [cited 2019 Feb 12]. Available from: http://www.asia-pacific.undp.org/content/rbap/en/ home/library/democratic_governance/hiv_aids/promoting-and-protectinghuman-rights-in-relation-to-sexual-orie/

3. Freeland R, Rogers E, van Rooyen H, Darbes L, Saylor K, Stephenson R. Measurements of sexuality-based stigma among gay, bisexual, and other men who have sex with men (GBMSM) in resource poor settings: a review. AIDS Behav. 2018;22(5):1614-38. https://doi.org/10.1007/s10461-017-1975-3.

4. Poteat T, Ackerman B, Diouf D, Ceesay N, Mothopeng T, Odette KZ, et al. HIV prevalence and behavioral and psychosocial factors among transgender women and cisgender men who have sex with men in 8 African countries: a cross-sectional analysis. PLoS Med. 2017;14(11):e1002422. https://doi.org/1 0.1371/journal.pmed.1002422.

5. Brennan DJ, Bauer GR, Bradley K, Tran OV. Methods used and topics addressed in quantitative Health Research on gay, bisexual and other men who have sex with men: a systematic review of the literature. J Homosex. 2017;64(11):1519-38. https://doi.org/10.1080/00918369.2016.1247537.

6. Tantirattanakulchai $P$, Hounnaklang N. Perceived social support and its relationship with depression among Bangkok's trans women. J Health Res. 2021. Online ahead of print. https://doi.org/10.1108/JHR-05-2020-0165.
7. Patel S, Prabhakar P, Saggurti N. Factors associated with mental depression among men who have sex with men in southern India. Health. 2015;7(09): 1114-23. https://doi.org/10.4236/health.2015.79127.

8. Vu N, Holt M, Phan H, La L, Tran G, Doan T, et al. Amphetamine-typestimulants (ATS) use and homosexuality-related enacted stigma are associated with depression among men who have sex with men (MSM) in two major cities in Vietnam in 2014. Subst Use Misuse. 2017:52(11):1411-9. https://doi.org/10.1080/10826084.2017.1284233.

9. Chakrapani V, Scheim A, Newman P, Shunmugam M, Rawat S, Baruah D, et al. Affirming and negotiating gender in family and social spaces: Stigma, mental health and resilience among transmasculine people in India. Cult Health Sex. 2021. Online ahead of print. https://doi.org/10.1080/13691058.2 021.1901991.

10. Salway T, Ross LE, Fehr CP, Burley J, Asadi S, Hawkins B, et al. A systematic review and Meta-analysis of disparities in the prevalence of suicide ideation and attempt among bisexual populations. Arch Sex Behav. 2019;48(1):89111. https://doi.org/10.1007/s10508-018-1150-6.

11. Plöderl M, Tremblay P. Mental health of sexual minorities. A systematic review. Int Rev Psychiatry. 2015;27(5):367-85. https://doi.org/10.3109/095402 61.2015.1083949.

12. Mathy R. Suicidality and sexual orientation in five continents: Asia, Australia, Europe, North America, and South America. Int J Sex Gend Stud. 2002;7(2/ 3):215-25. https://doi.org/10.1023/A:1015853302054.

13. Hall WJ. Psychosocial risk and protective factors for depression among lesbian, gay, bisexual, and queer youth: a systematic review. J Homosex. 2018;65(3):263-316. https://doi.org/10.1080/00918369.2017.1317467.

14. McParland J, Camic PM. Psychosocial factors and ageing in older lesbian, gay and bisexual people: a systematic review of the literature. J Clin Nurs. 2016;25(23-24):3415-37. https://doi.org/10.1111/jocn.13251.

15. Marshall E, Claes L, Bouman WP, Witcomb GL, Arcelus J. Non-suicidal self-injury and suicidality in trans people: a systematic review of the literature. Int Rev Psychiatry. 2016;28(1):58-69. https://doi.org/10.3109/09540261.2015.1073143.

16. Krueger EA, Meyer $\mathrm{H}$, Upchurch $\mathrm{CH}$. Sexual orientation group differences in perceived stress and depressive symptoms among young adults in the United States. LGBT Health. 2018;5(4):242-9. https://doi.org/10.1089/lgbt.201 7.0228 .

17. Ha H, Ross M, Risser JM, Nguyen HT. Determinants of homosexuality-related stigma among men who have sex with men in Hanoi. Vietnam Int J Sex Health. 2014;26(3):200-16. https://doi.org/10.1080/19317611.2013.858802.

18. Ha H, Risser JM, Ross MW, Huynh NT, Ngyen HT. Homosexuality- related stigma and sexual risk behaviors among men who have sex with men in Hanoi. Vietnam Arch Sex Behav. 2015;44(2):349-56. https://doi.org/10.1007/ s10508-014-0450-8.

19. Philbin MM, Hirsch JS, Wilson PA, Ly AT, Giang LM, Parker RG. Structural barriers to HIV prevention among men who have sex with men (MSM) in Vietnam: diversity, stigma, and healthcare access. PLoS One. 2018;13(4): e0195000. https://doi.org/10.1371/journal.pone.0195000.

20. Thompson LH, Shamshad K, du Plessis E, Lazarus L, Reza-Paul S, Hafeez Ur Rahman S, et al. Beyond internalised stigma: daily moralities and subjectivity among self-identified kothis in Karnataka, South India. Cult Health Sex. 2013; 15(10):1237-51. https://doi.org/10.1080/13691058.2013.818714.

21. United Nations Development Programme, Asia Pacific Transgender Network. Legal gender recognition: a multi-country legal and policy review in Asia [internet]. Bangkok: United Nations Development Programme; 2017 [cited 2019 Feb 12]. Available from: http://www.asia-pacific.undp.org/ content/rbap/en/home/library/democratic_governance/hiv_aids/legalgender-recognition\%2D\%2Da-multi-country-legal-and-policy-revie.html

22. Mendos LR. State-Sponsored Homophobia 2019 [Internet]. Geneva: International Lesbian, Gay, Bisexual, Trans and Intersex Association; 2019. [cited 2019 Apr 18]. Available from: https://ilga.org/downloads/ILGA_State_ Sponsored_Homophobia_2019.pdf

23. Winter S, Davis-McCabe C, Russell C, Wilde D, Chu TH, Suparak P, et al. Denied work: an audit of employment discrimination on the basis of gender identity in South-East Asia [internet]. Bangkok: Asia Pacific Transgender Network and United Nations Development Programme; 2018. [cited 2019 Feb 12]. Available from: https://www.undp.org/content/dam/rba p/docs/Research\%20\&\%20Publications/hiv_aids/RBAP-HHD-2018-DeniedWork-An-Audit-of-Employment-Discrimination.pdf

24. Gazette N. The constitution of Nepal [internet]. Kathmandu: Nepal Law Commission; 2015. [cited 2019 Feb 14]. Available from: https://www.mohp. gov.np/downloads/Constitution\%20of\%20Nepal\%202072_full_english.pdf 
25. United Nations Development Programme, United States Agency for International Development. Being LGBT in Asia: Nepal Country Report [Internet]. Bangkok: UNDP Asia-Pacific Regional Centre; 2014. [cited 2018 Oct 25]. Available from: http://www.asia-pacific.undp.org/content/dam/rba p/docs/Research\%20\&\%20Publications/hiv_aids/rbap-hhd-2014-blia-nepalcountry-report.pdf

26. Mahato R. The movement for human rights for sexual and gender minorities in Nepal: the beginning, 2001-2015 [master's thesis on the internet]. Worcester: Clark University; 2017. [cited 2018 Oct 25]. Available from: https://commons.clarku.edu/idce_masters_papers/148/

27. Boyce P, Pant S. Rapid ethnography of male to male sexuality and sexual health [internet]. Kathmandu: Family Health International; 2001. [cited 2019 Mar 05]. Available from: https://www.who.int/hiv/topics/vct/sw_toolkit/ ethnography_male_male_sexuality.pdf

28. Oli N, Onta SR. Self-perception of stigma and discrimination among men having sex with men. J Nepal Health Res Counc. 2012;10(22):197-200.

29. Network APT. From barriers to bridges: increasing access to HIV and other health services for trans people in Asia [internet]. Bangkok: Asia Pacific Transgender Network; 2017. [cited 2019 Feb 12]. Available from: http:// www.asia-pacific.undp.org/content/dam/rbap/docs/Research\%20\%26\%2 OPublications/hiv_aids/FBTB-Report-D3-Screen.pdf

30. Knight K. Bridges to justice: case study of LGBTI rights in Nepal [internet]. New York: Astrea Lesbian Foundation for Justice; 2015. [cited 2019 Feb 14] Available from: http://www.astraeafoundation.org/uploads/files/Astraea\%2 ONepal\%20Case\%20Study.pdf

31. Tomicic A, Gálvez C, Quiros C, Martínez C, Fontbona J, Rodríguez J, et al. Suicide in lesbian, gay, bisexual and trans populations: systematic review of a decade of research (2004-2014). Rev Med Chil. 2016;144(6):723-33. https:// doi.org/10.4067/S0034-98872016000600006.

32. Wilson E, Pant SB, Comfort M, Ekstrand M. Stigma and HIV risk among Metis in Nepal. Cult Health Sex. 2011;13(3):253-66. https://doi.org/10.1080/13691 058.2010 .524247

33. Kohlbrenner V, Deuba K, Karki DK, Marrone G. Perceived discrimination is an independent risk factor for suicidal ideation among sexual and gender minorities in Nepal. PLoS One. 2016;11(7):e0159359. https://doi.org/10.1371/ journal.pone.0159359.

34. Deuba K, Ekström AM, Shrestha R, lonita G, Bhatta L, Karki DK. Psychosocial health problems associated with increased HIV risk behavior among men who have sex with men in Nepal: a cross-sectional survey. PLoS One. 2013; 8(3):e58099. https://doi.org/10.1371/journal.pone.0058099.

35. Logie CH, Lacombe-Duncan A, Kenny KS, Levermore K, Jones N, Marshall A, et al. Associations between police harassment and HIV vulnerabilities among men who have sex with men and transgender women in Jamaica. Health Hum Rights. 2017;19(2):147-54.

36. Stall R, Mills T, Williamson J, Hart T, Greenwood G, Paul J, et al. Association of co-Occurring Psychosocial Health Problems and Increased Vulnerability to HIV/AIDS among urban men who have sex with men. Am J Public Health. 2003;93(6):939-42. https://doi.org/10.2105/AJPH.93.6.939.

37. National Centre for AIDS and STD Control. Integrated Biological and Behavioral Surveillance (IBBS) Survey among Men who have Sex with Men and Transgender in Tarai Highway District of Nepal- Round II [Internet]. Kathmandu: Ministry of Health and Population; 2018. [cited 2019 Feb 22]. Available from: https://www.aidsdatahub.org/sites/default/files/publication/ Nepal_Report_IBBS_MSM_TG_Terai_Highway_2018.pdf37.

38. Johnston LG, Sabin K. Sampling hard-to-reach populations with respondent driven sampling. Method Innov. 2010;5(2):38-48.

39. Krieger N. Racial and gender discrimination: risk factors for high blood pressure. Soc Sci Med. 1990;30(12):1273-81. https://doi.org/10.1016/02779536(90)90307-E.

40. United Nations Development Programme, Williams Institute. Surveying Nepal's sexual and gender minorities: an inclusive approach- executive summary [internet]. Bangkok: UNDP Asia-Pacific Regional Centre; 2014. [cited 2019 Feb 14]. Available from: https://www.undp.org/content/dam/rba p/docs/Research\%20\&\%20Publications/hiv_aids/rbap-hhd-2014-surveyingnepals-sexual-and-gender-minorities-executive-summary.pdf

41. Eaton W, Muntaner C, Smith C, Tien A, Ybarra M. Center of Epidemiologic Studies Depression Scale: review and revision (CESD and CESD-R). In: Maruish $M$, editor. The use of psychological testing for treatment planning and outcomes assessment. 3rd ed. Mahwah, NJ: Lawrence Erlbaum Associates; 2004. p. 363-77.
42. American Psychiatric Association. Diagnostic and statistical manual of mental disorders: DSM-5. Washington, D.C.: American Psychiatric Association; 2013. https://doi.org/10.1176/appi.books.9780890425596.

43. Nabbe P, Le Reste JY, Guillou-Landreat M, Munoz Perez MA, Argyriadou S, Claveria A, et al. Which DSM validated tools for diagnosing depression are usable in primary care research? A systematic literature review. Eur Psychiatry. 2017;39:99-105. https://doi.org/10.1016/j.eurpsy.2016.08.004.

44. Van Dam NT, Earleywine M. Validation of the Center for Epidemiologic Studies Depression Scale-Revised (CESD-R): pragmatic depression assessment in the general population. Psychiatry Res. 2011;186(1):128-32. https://doi.org/10.1016/j.psychres.2010.08.018.

45. Hequembourg AL, Panagakis C. Maximizing respondent-driven sampling field procedures in the recruitment of sexual minorities for health research. SAGE Open Med. 2019;7:1-13.

46. Chakrapani V, Newman PA, Shunmugam M, Logie CH, Samuel M. Syndemics of depression, alcohol use, and victimisation, and their association with HIV- related sexual risk among men who have sex with men and transgender women in India. Glob Public Health. 2017;12(2):25065. https://doi.org/10.1080/17441692.2015.1091024.

47. Safren S, Thomas B, Mimiaga M, Chandrasekaran V, Menon S, Swaminathan $S$, et al. Depressive symptoms and human immunodeficiency virus risk behavior among men who have sex with men in Chennai. India Psychol Health Med. 2009;14(6):705-15. https://doi.org/10.1080/13548500903334754.

48. Hebbar $Y$, Singh B. Psychiatric morbidity in a selective sample of transgenders in Imphal, Manipur: a descriptive study. Ann Indian Psychiatry. 2017;1(2):114-7. https://doi.org/10.4103/aip.aip_24_17.

49. Kota K, Salazar L, Culbreth R, Crosby R, Jones J. Psychosocial mediators of perceived stigma and suicidal ideation among transgender women. BMC Public Health. 2020;20(1):125. https://doi.org/10.1186/s12889-020-8177-z.

50. Wilton L, Chiasson M, Nandi V, Lelutiu-Weinberger C, Frye V, Hirshfield S, et al. Characteristics and correlates of lifetime suicidal thoughts and attempts among young black men who have sex with men (MSM) and transgender women. J Black Psychol. 2018;44(3):273-90. https://doi.org/1 $0.1177 / 0095798418771819$

51. Secor A, Wahome E, Micheni M, Rao D, Simoni J, Sanders E, et al. Depression, substance abuse and stigma among men who have sex with men in coastal Kenya. AIDS. 2015;29(Supplement 3):S251-9. https://doi.org/1 0.1097/QAD.0000000000000846.

52. Ryan C, Huebner D, Diaz R, Sanchez J. Family rejection as a predictor of negative health outcomes in white and Latino lesbian, gay, and bisexual young adults. Pediatrics. 2009;123(1):346-52. https://doi.org/10.1542/peds.2 007-3524

53. Srivastava A, Davis JP, Patel P, Daniel EE, Karkal S, Rice E. Polyvictimization, Sex Work, and Depressive Symptoms Among Transgender Women and Men Who Have Sex With Men. J Interpers Violence. 2021. Online ahead of print. https://doi.org/10.1177/0886260521990840.

54. Clements-Nolle K, Marx R, Katz M. Attempted suicide among transgender persons: the influence of gender-based discrimination and victimization. J Homosex. 2006;51(3):53-69. https://doi.org/10.1300/J082v51n03_04.

55. Meyer $\mathbb{H}$. Prejudice, social stress, and mental health in lesbian, gay, and bisexual populations: conceptual issues and research evidence. Psychol Bull. 2003;129(5):674-97. https://doi.org/10.1037/0033-2909.129.5.674.

\section{Publisher's Note}

Springer Nature remains neutral with regard to jurisdictional claims in published maps and institutional affiliations.

Ready to submit your research? Choose BMC and benefit from:

- fast, convenient online submission

- thorough peer review by experienced researchers in your field

- rapid publication on acceptance

- support for research data, including large and complex data types

- gold Open Access which fosters wider collaboration and increased citations

- maximum visibility for your research: over $100 \mathrm{M}$ website views per year

At BMC, research is always in progress.

Learn more biomedcentral.com/submission 